\title{
Myopia in secondary school students in Mwanza City, Tanzania: the need for a national screening programme
}

\author{
S H Wedner, D A Ross, J Todd, A Anemona, R Balira, A Foster
}

Br J Ophthalmol 2002;86:1200-1206

Series editors: W V Good and S Ruit

See end of article for authors' affiliations

........................

Correspondence to: Dr Susanne Wedner, c/o Eloise Turner, Infectious

Diseases and Epidemiology

Unit, London School of

Hygiene and Tropical

Medicine, Keppel Street,

London WC IE 7HT, UK;

susanne.wedner@gmx.net

Accepted for publication 11 March 2002
Background/aims: The prevalence of significant refractive errors and other eye diseases was measured in 2511 secondary school students aged 11-27 years in Mwanza City, Tanzania. Risk factors for myopia were explored.

Methods: A questionnaire assessed the students' socioeconomic background and exposure to near work followed by visual acuity assessment and a full eye examination. Non-cycloplegic objective and subjective refraction was done on all participants with visual acuity of worse than $6 / 12$ in either eye without an obvious cause.

Results: $154(6.1 \%)$ students had significant refractive errors. Myopia was the leading refractive error $(5.6 \%)$. Amblyopia $(0.4 \%)$, strabismus $(0.2 \%)$, and other treatable eye disorders were uncommon. Only $30.3 \%$ of students with significant refractive errors wore spectacles before the survey. Age, sex, ethnicity, father's educational status, and a family history of siblings with spectacles were significant independent risk factors for myopia.

Conclusion: The prevalence of uncorrected significant refractive errors is high enough to justify a regular school eye screening programme in secondary schools in Tanzania. Risk factors for myopia are similar to those reported in European, North-American, and Asian populations. p developed countries, screening for eye diseases in preschool and schoolchildren is done routinely. In the United Kingdom, almost all children with important visual problems have been detected before school entry, ${ }^{1}$ and by the age of 8 years only $1.7 \%$ of children have not been screened for eye diseases. ${ }^{2}$ Eye services are easily accessible, and the majority of children with eye problems consult them without requiring referral by other health professionals. ${ }^{3}$

However, little is known about the prevalence and public health importance of eye diseases in school age children in developing countries. No national preschool or school eye screening programme exists in Tanzania nor in most other countries in sub-Saharan Africa.

A recent eye survey in 1386 primary school children in three schools in rural Mwanza Region, Tanzania, showed a low prevalence of significant refractive errors causing visual acuity of worse than $6 / 12$ in either eye (1.0\%), of amblyopia $(0.2 \%)$, and of strabismus $(0.5 \%) .{ }^{4}$ All pupils with significant refractive errors were myopic. Except for active trachoma, which was common in one of the primary schools (15.5\%) and $5.5 \%$ overall, other eye diseases were rare. The low prevalence of significant refractive errors combined with results of other surveys in sub-Saharan Africa, ${ }^{5}$ cast doubt on whether school eye screening for refractive errors in primary schools would be cost effective in rural sub-Saharan Africa.

Myopia has been associated with socioeconomic status, level and length of education, parental myopia, and the exposure to near work. ${ }^{5-10}$ A higher prevalence of myopia would therefore be expected in urban African secondary school students than in rural primary school students.

The Mwanza secondary school study reported here attempted:

(1) To measure the prevalence of significant refractive errors leading to visual acuity of worse than 6/12 in either eye and of other eye diseases in secondary school students in Mwanza City

(2) To evaluate factors associated with myopia in an urban population of secondary school students in Tanzania
(3) To make recommendations to the Tanzanian education and health authorities on whether they should introduce an eye screening programme for secondary school students.

\section{MATERIALS AND METHODS}

\section{Study population and study site}

Mwanza City is situated on the southern shore of Lake Victoria. It is the second largest city in Tanzania with an estimated 400000 inhabitants. It has 53 secondary schools with approximately 7000 students. ${ }^{11}$ Five schools were purposively selected of these to participate in the study. Four of the schools are private and three of these (Isamilo, Victoria, and Lake Secondary) have a relatively high intake of non-African students (Table 1). Thaqaafa Secondary is a private school mainly attended by Africans. Mwanza Secondary is a big state run secondary school, which is nearly exclusively attended by African children and thought to be reasonably representative of urban state run secondary schools in Tanzania. All the students attending these five secondary schools were eligible to participate in the study.

\section{Questionnaire and eye examination}

The survey took place from April to May 2001. Information leaflets explaining the study procedure and its aim were distributed to all students and their parents before beginning the examination. Parents were asked to inform the head teacher and the student if they did not want their child to participate. All the students who agreed to participate had to give written consent. A detailed questionnaire in the child's preferred language (Swahili or English) was administered. The two versions of the questionnaire were subjected to repeated back translation to ensure that they were similar. The questionnaire was followed by an eye examination. The team performing the examination consisted of six trained secondary school leavers (completed sixth form), one ophthalmic nurse, one optometrist, and one ophthalmologist (SW). Research and ethics approval was obtained from the government of Tanzania through its medical research coordinating committee, and from the ethics committee of the London School of Hygiene and Tropical Medicine. Consent for the study was also obtained from the regional 
health and education authorities, and from the participating schools and parents.

The questionnaire contained questions about the ethnic and social background as well as detailed information about the student's exposure to near work. Questions about ethnicity also included information about the length of time that the student's paternal and maternal family had lived in Tanzania. Indicators such as parental education, occupation, and property (house, television, computer, car, etc.) were used to evaluate their socioeconomic background. Questions about the different types of near work included the number of hours they spent reading for pleasure, studying outside school hours, watching television, using a computer (work or games), and doing needlework. The students estimated the average number of hours they spent doing each of these per week (weekdays and weekend) separately for term time and holidays. When necessary, they were helped to do this by the interviewers. In addition, they were asked to estimate the number of hours they had spent doing each of these activities during the last school week. In the analysis, variables for reading for pleasure and for studying were then combined giving three times as much weight to term time as to holidays, because term time takes up approximately three quarters of the year. Watching television, working on a computer, and needlework were analysed separately, because they are usually performed at different working distances. ${ }^{12}$

On the same day, a second interviewer (QC interview) who was not aware of the results of the first interview repeated a $10 \%$ randomly chosen sample of questionnaires. Any important discrepancies between the results of the two interviews were clarified by the ophthalmologist.

Having completed the questionnaire, the students then had their visual acuity (VA) checked by the ophthalmic nurse. Both eyes were tested separately using Snellen's E chart at 6 metres in a well lit room. A line on the chart was accepted as being read if the direction of more than half the optotypes had been identified correctly. If the VA was below 6/12 in one or both eyes, a pinhole test was performed.

Using a torch and direct ophthalmoscopy, the ophthalmologist inspected all the students' eyes for abnormalities of position and motility, the anterior segment, the optic disc, and the macula. If a diagnosis could not be established through inspection, a thorough eye examination including biomicroscopy with a portable Zeiss slit lamp, indirect ophthalmoscopy with mydriasis, and Schiøtz tonometry were performed as appropriate.

Everybody with suspected refractive errors underwent non-cycloplegic objective and subjective refraction by the optometrist. Objective refraction was done by static retinoscopy in a slightly darkened room. Results were confirmed by subjective refraction, accepting the lowest minus value leading to a measurable increase and the highest plus value not leading to a measurable decrease in VA. Astigmatism was measured using minus cylinders. The subjective refraction results were used for the analyses presented here except where this would have been unreliable-for example, due to combined pathology. In these three cases the retinoscopy results were used. Spectacles and any treatment needed were provided free of charge.

\section{Statistical methods}

All data were double entered on to computers by two data entry clerks and checked for discrepancies to minimise data entry errors. Range and consistency checks were performed on all data. DBAse 4 (Borland International, Scotts Valley, CA, USA), STATA 6.0, and STATA 7.0 (Stata Corporation, College Station, TX, USA) were used for data entry and analysis.

Prevalence was calculated for each of the eye disorders. Relations between myopia and potential risk factors were measured using prevalence ratios. Means and medians were calculated for continuous variables. $\chi^{2}$ Tests and Fisher's exact test were used as appropriate to test whether potential risk factors were significantly associated with myopia. $t$ Tests and Wilcoxon's rank sum test were used to compare means and medians respectively. Two tailed tests were used throughout. The repeatability of the near work variables (original versus QC interviews) was tested using the kappa statistic. A kappa value of $<0.2$ was interpreted as showing poor agreement, $0.21-0.40$ fair agreement, 0.41-0.60 moderate agreement, 0.61-0.80 good agreement, and $0.81-1.00$ very good agreement. ${ }^{13}$

Logistic regression was used to identify independent risk factors for myopia. Odds ratios (OR) and 95\% confidence intervals $(95 \% \mathrm{CI})$ were calculated for risk factors that were independently associated with myopia in this population.

\section{RESULTS}

\section{Study population}

Out of the 2810 secondary school students who were eligible to participate in the study, 2511 students (89.4\%) were screened for eye diseases, 262 students (9.3\%) were absent, and 37 students ( $1.3 \%)$ refused to participate. The proportion of students who were not examined ranged from $3.6 \%$ to $13.7 \%$ by school (Table 1 ). Fifty nine per cent of the students examined were male. Their ages ranged from 11 to 27 years, with the great majority of students between 14 and 19 years $(84.0 \%)$ (Table 1$)$. Ninety per cent of the students examined were Africans and for $98 \%$ of the African students both of their parents originated from Tanzania. Of the 253 nonAfrican students, more than half (141) were Asians, 40 were Arabs, four were white, and 68 of mixed ethnicity. Most of their families had been living in Africa for at least two generations (50 years). This was the case for $80.1 \%$ (113/141) of the Asians, $95 \%$ of the Arabs, and $100 \%$ of the mixed students. Almost half of the students (45.5\%) attended Mwanza Secondary School (Table 1).

Information about sex and ethnicity was available for all the 299 students who were not examined and data on age were available for 246 of them (82\%). Missing students were more likely to be male $(74 \% v .59 \%, \mathrm{p}<0.001$; two sample test of proportions) and African (97\% v90\%, p<0.001), and, on average, were older than participants ( $\geqslant 17$ years: $207 / 246=84.1 \% v$ $1090 / 2511=43.4 \% ; p<0.001$; two sample test of proportions).

\section{Prevalence of eye diseases}

Except in four students, all those with poor visual acuity without an obvious cause had both objective and subjective refraction performed. In three students subjective refraction was unlikely to be valid because they had refractive errors combined with other pathology. In these students the retinoscopy results were used. In one myopic student, only subjective refraction was performed. Agreement between objective and subjective refraction was excellent. Ninety six per cent of spherical values obtained by subjective refraction were within plus or minus 0.25 dioptres of the objective findings, and none was more than 0.5 dioptres different. No student was classified as myopic by objective refraction and non-myopic by subjective refraction or vice versa.

Poor eyesight, defined as uncorrected unilateral or bilateral visual acuity (VA) of worse than 6/12 was present in 174/251 1 $(6.9 \%)$ students. Five per cent of students had bilateral poor eyesight and $2 \%$ had unilateral poor eyesight (Table 2 ). Three students had severe visual impairment (uncorrected VA $<6 / 60$ in the better eye). The main cause of poor eyesight was significant refractive error with a prevalence of $6.1 \%$, being responsible for $88.5 \%$ of all causes of poor eyesight (Table 2 ). The majority of students with refractive errors were myopic (141/154, 91.6\%). The prevalence of significant myopia was $5.6 \%$. Astigmatism was also present in 49 of the 141 myopic students $(34.8 \%)$. The three students with severe visual impairment were all myopic. Hyperopia and astigmatism alone causing poor eyesight $(\mathrm{VA}<6 / 12)$ were both rare $(0.4 \%$ 
Table 1 Profiles of the study secondary schools

\begin{tabular}{|c|c|c|c|c|c|c|}
\hline & \multicolumn{5}{|l|}{ Schools } & \multirow[t]{2}{*}{ Total } \\
\hline & Isamilo & Victoria & Lake & Thaqwaafa & Mwanza & \\
\hline & No (\%) & No (\%) & No (\%) & No (\%) & No (\%) & No (\%) \\
\hline \multicolumn{7}{|l|}{ Sex } \\
\hline Male & (52.5) & $35(66.0)$ & $18(67.2)$ & 491 (62.9) & $605(52.9)$ & $1481(59.0)$ \\
\hline Female & 2 & ) & .8) & 2901 & $538(47.1)$ & $1030(41.0)$ \\
\hline \multicolumn{7}{|l|}{ Ethnicity } \\
\hline African & $6(9.8)$ & 10 (18.9) & 402 (85.0) & $707(90.5)$ & $1133(99.1)$ & 2258 (89.9) \\
\hline South Asian & $38(62.3)$ & $35(66.0)$ & $60(12.7)$ & $6(0.8)$ & $2(0.2)$ & $141(5.6)$ \\
\hline Arab & $0(0.0)$ & $5(9.4)$ & $3(0.6)$ & $30(3.8)$ & $2(0.2)$ & $40(1.6)$ \\
\hline White & 1601 & '́⿴囗十⺝ & 0 in & $0(0.0)$ & $0(0.0)$ & $4(0.2)$ \\
\hline Mixed & $13(21.3)$ & $3(5.7)$ & $8(1.7)$ & $38(4.9)$ & $6(0.5)$ & $68(2.7)$ \\
\hline \multicolumn{7}{|l|}{ Age (years) } \\
\hline $11-13$ & $4(72.1)$ & $19(35.9)$ & $21(4.4)$ & $51(6.5)$ & $50(4.4)$ & $185(7.4)$ \\
\hline $14-16$ & 17 (27.9) & $32(60.4)$ & $199(42.1)$ & $464(59.4)$ & $524(45.8)$ & $1236(49.2)$ \\
\hline $17-19$ & $0(0.0)$ & $2(3.8)$ & 164 (34.7) & 242 (31.0) & $466(40.8)$ & $874(34.8)$ \\
\hline $20+$ & $0(0.0)$ & $0(0.0)$ & $89(18.8)$ & $24(3.1)$ & $103(9.0)$ & $216(8.6)$ \\
\hline Significant myopia * & $9(14.8)$ & $10(18.9)$ & $28(5.9)$ & $40(5.1)$ & $54(4.7)$ & $141(5.6)$ \\
\hline Missing or refused & $5(7.6)$ & $2(3.6)$ & 75 (13.7) & $95(10.8)$ & $122(9.6)$ & $299(10.6)$ \\
\hline Total & $61(2.4)$ & $53(2.1)$ & $473(18.8)$ & 781 (31.1) & $1143(45.5)$ & $2511(100)$ \\
\hline
\end{tabular}

*Causing visual acuity of worse than $6 / 12$ in one or both eyes.

Table 2 Causes of poor eyesight (visual acuity worse than 6/12)

\begin{tabular}{|c|c|c|c|}
\hline \multirow[b]{2}{*}{ Causes } & \multirow{2}{*}{$\begin{array}{l}\begin{array}{l}\text { Unilateral poor } \\
\text { eyesight }\end{array} \\
\text { No }(\%) \ddagger\end{array}$} & \multirow{2}{*}{$\begin{array}{l}\begin{array}{l}\text { Bilateral poor } \\
\text { eyesight* }\end{array} \\
\text { No }(\%) \ddagger\end{array}$} & \multirow{2}{*}{$\begin{array}{l}\text { Total* } \\
\text { No (\%) }\end{array}$} \\
\hline & & & \\
\hline \multicolumn{4}{|l|}{ Refractive errors } \\
\hline myopia +/- astigmatism * & $24(0.96)$ & $117(4.66)$ & $141(5.62)$ \\
\hline hyperopia +/- astigmatism & $7(0.28)$ & $3(0.12)$ & $10(0.40)$ \\
\hline astigmatism only & $2(0.08)$ & $1(0.04)$ & $3(0.12)$ \\
\hline refractive error and amblyopia $\dagger$ & $3(0.12)$ & $4(0.16)$ & $7(0.28)$ \\
\hline Subtotal & $33(1.31)$ & $121(4.82)$ & $154(6.13)$ \\
\hline \multicolumn{4}{|l|}{ Anterior segment } \\
\hline corneal scar & $3(0.12)$ & $0(0.00)$ & $3(0.12)$ \\
\hline cataract & $1(0.04)$ & $0(0.00)$ & $1(0.04)$ \\
\hline aphakia and amblyopia & $0(0.00)$ & $1(0.04)$ & $1(0.04)$ \\
\hline Subtotal & $4(0.16)$ & $1(0.04)$ & $5(0.20)$ \\
\hline \multicolumn{4}{|l|}{ Posterior segment } \\
\hline optic atrophy* & $3(0.12)$ & $4(0.16)$ & $7(0.28)$ \\
\hline optic nerve coloboma & $1(0.04)$ & $0(0.00)$ & $1(0.04)$ \\
\hline retinopathy or maculopathy or macular scars & $6(0.24)$ & $0(0.00)$ & $6(0.24)$ \\
\hline Subtotal & $10(0.40)$ & $4(0.16)$ & $14(0.56)$ \\
\hline \multicolumn{4}{|l|}{ Others } \\
\hline strabismic amblyopia & $1(0.04)$ & $0(0.00)$ & $1(0.04)$ \\
\hline phthisis & $1(0.04)$ & $0(0.00)$ & $1(0.04)$ \\
\hline Subtotal & $2(0.08)$ & $0(0.00)$ & $2(0.08)$ \\
\hline Total & 49 (1.95) & $125(4.98)$ & $174(6.93)$ \\
\hline
\end{tabular}

and $0.1 \%$, respectively), as were other non-refractive causes of poor eyesight $(0.8 \%)$. Strabismus $(0.2 \%)$ and amblyopia $(0.4 \%)$ were rare (Table 2$)$.

Other eye diseases that did not cause poor eyesight were also rare: eight students had disorders of the lids or conjunctiva (stye (two), vernal keratoconjunctivitis (two), bacterial conjunctivitis (one); corneal foreign body (one), pterygium (two)), and two students had abnormalities of the iris (iris coloboma (one), iris tumour (one)).

\section{Significant myopia: associations with age, sex,}

\section{ethnicity, and socioeconomic factors}

Significant myopia (causing unilateral or bilateral $\mathrm{VA}<6 / 12$ ) was commoner in students who were female (PR: 1.59, $\mathrm{p}=0.004)$, in the youngest age group of $11-13$ years (PR: 2.71, $\mathrm{p}<0.001$ ), non-African (PR: $2.84, \mathrm{p}<0.001$ ), whose father had post-secondary education (PR: $1.56, \mathrm{p}=0.009$ ), and who had a family history of sibling(s) wearing spectacles (PR:1.70, $p=0.002$ ) (Table 3). These five risk factors all remained significant in a multivariate analysis (Table 4 ) that included all risk factors that were significantly associated with myopia $(\mathrm{p}<0.05)$ in the univariate analysis, except for use of spectacles as this is more likely to be a consequence of the refractive error than the cause of it. Father's and mother's occupation, mother's education, both parents speaking English, ownership or use of various high status possessions, type of housing, and exposure to near work were all significantly associated in the univariate 
Table 3 Demographic and socioeconomic factors associated with significant myopia

\begin{tabular}{|c|c|c|c|c|c|}
\hline Variable & No & $\begin{array}{l}\text { Significant myopia } \\
(\%)\end{array}$ & Prevalence ratio & $\begin{array}{l}\text { Confidence interval } \\
(95 \%)\end{array}$ & p Value* \\
\hline \multicolumn{6}{|l|}{ Sex } \\
\hline Male & 1481 & 4.5 & 1.0 & - & - \\
\hline Female & 1030 & 7.2 & 1.6 & 1.2 to 2.2 & 0.004 \\
\hline \multicolumn{6}{|l|}{ Age (years) } \\
\hline $11-13$ & 185 & 14.1 & 2.7 & 1.8 to 4.2 & $<0.001$ \\
\hline $14-16$ & 1236 & 5.2 & 1.0 & - & - \\
\hline $17+$ & 1090 & 4.7 & 0.9 & 0.6 to 1.3 & 0.580 \\
\hline \multicolumn{6}{|l|}{ Ethnic group } \\
\hline African & 2258 & 4.7 & 1.0 & - & - \\
\hline \multicolumn{6}{|l|}{ Non-African } \\
\hline South-Asian & 141 & 17.0 & 3.6 & 2.4 to 5.4 & $<0.001$ \\
\hline Arab & 40 & 10.0 & 2.1 & 0.8 to 5.5 & $0.124 \dagger$ \\
\hline White & 4 & 25.0 & 5.3 & 1.0 to 29.1 & $0.178 \dagger$ \\
\hline Mixed & 68 & 7.4 & 1.6 & 0.7 to 3.7 & 0.321 \\
\hline Total & 253 & 13.4 & 2.8 & 2.0 to 4.1 & $<0.001$ \\
\hline \multicolumn{6}{|l|}{ Father's occupation } \\
\hline Unskilled work & 357 & 3.1 & 1.0 & - & - \\
\hline Skilled work & 493 & 5.7 & 1.8 & 0.9 to 3.7 & 0.074 \\
\hline Trading & 684 & 7.0 & 2.3 & 1.2 to 4.3 & 0.009 \\
\hline Professional & 760 & 6.1 & 2.0 & 1.0 to 3.8 & 0.035 \\
\hline Unknown or dead & 217 & 3.7 & 1.2 & 0.5 to 2.9 & 0.692 \\
\hline \multicolumn{6}{|l|}{ Mother's occupation } \\
\hline Unskilled work & 316 & 4.4 & 1.0 & - & - \\
\hline Skilled work & 256 & 5.9 & 1.3 & 0.7 to 2.7 & 0.439 \\
\hline Trading & 482 & 3.3 & 0.8 & 0.4 to 1.5 & 0.420 \\
\hline Professional & 450 & 4.2 & 1.0 & 0.5 to 1.9 & 0.889 \\
\hline Housewife & 944 & 7.7 & 1.8 & 1.0 to 3.1 & 0.045 \\
\hline Unknown or dead & 63 & 6.4 & 1.4 & 0.5 to 4.2 & 0.385 \\
\hline \multicolumn{6}{|l|}{ Father's education } \\
\hline Secondary or less & 1231 & 4.7 & 1.0 & - & - \\
\hline Post-secondary & 924 & 7.4 & 1.6 & 1.1 to 2.2 & 0.009 \\
\hline Unknown or dead & 356 & 4.2 & 0.9 & 0.5 to 1.6 & 0.698 \\
\hline \multicolumn{6}{|l|}{ Mother's education } \\
\hline Primary or none & 1224 & 4.6 & 1.0 & - & - \\
\hline Secondary & 530 & 7.4 & 1.6 & 1.1 to 2.4 & 0.018 \\
\hline Post-secondary & 571 & 6.8 & 1.5 & 1.0 to 2.2 & 0.047 \\
\hline Unknown or dead & 186 & 3.8 & 0.8 & 0.4 to 1.8 & 0.618 \\
\hline \multicolumn{6}{|l|}{ Parents speak English } \\
\hline None & 560 & 3.6 & 1.0 & - & - \\
\hline Father only & 885 & 5.4 & 1.5 & 0.9 to 2.5 & 0.105 \\
\hline Mother only & 158 & 4.4 & 1.2 & 0.5 to 2.9 & 0.616 \\
\hline Both & 899 & 7.4 & 2.1 & 1.3 to 3.4 & 0.003 \\
\hline Unknown or dead & 9 & 0.0 & 0.0 & - & $1.000 \dagger$ \\
\hline \multicolumn{6}{|l|}{ Parents own a: } \\
\hline Car & & & & & \\
\hline no & 1808 & 4.9 & 1.0 & - & - \\
\hline yes & 703 & 7.5 & 1.6 & 1.1 to 2.2 & 0.009 \\
\hline Television & & & & & \\
\hline no & 811 & 3.8 & 1.0 & - & - \\
\hline yes & 1700 & 6.5 & 1.7 & 1.2 to 2.5 & 0.007 \\
\hline Computer & & & & & \\
\hline no & 2284 & 5.2 & 1.0 & - & - \\
\hline yes & 227 & 9.7 & 1.9 & 1.2 to 2.9 & 0.005 \\
\hline Parents have use of a & & & & & \\
\hline Car & & & & & \\
\hline no & 1465 & 4.6 & 1.0 & - & - \\
\hline yes & 1046 & 7.1 & 1.6 & 1.1 to 2.1 & 0.007 \\
\hline Home: & & & & & \\
\hline Owned & & & & & \\
\hline no & 466 & 8.2 & 1.0 & - & - \\
\hline yes & 2045 & 5.0 & 0.6 & 0.4 to 0.9 & 0.008 \\
\hline Rented & & & & & \\
\hline no & 2026 & 5.3 & 1.0 & - & - \\
\hline yes & 485 & 6.8 & 1.3 & 0.9 to 1.9 & 0.205 \\
\hline Provided free & & & & & \\
\hline no & 2266 & 5.3 & 1.0 & - & - \\
\hline yes & 245 & 9.0 & 1.7 & 1.1 to 2.6 & 0.016 \\
\hline Sibling(s) with specta & & & & & \\
\hline no & 1916 & 4.8 & 1.0 & - & - \\
\hline yes & 570 & 8.1 & 1.7 & 1.2 to 2.4 & 0.002 \\
\hline No siblings & 25 & 16.0 & 3.4 & 1.3 to 8.5 & $0.031 \dagger$ \\
\hline
\end{tabular}


Table 4 Independent risk factors for myopia-multivariate analysis

\begin{tabular}{|c|c|c|c|c|c|c|}
\hline Categories & Prevalence & $O R^{*}$ & $95 \% \mathrm{Cl}$ & $\begin{array}{l}\text { Adjusted } \\
\text { OR† }\end{array}$ & $95 \% \mathrm{Cl}$ & $\mathrm{p}$ Vaue \\
\hline \multicolumn{7}{|l|}{ Ethnic group } \\
\hline Africans & 4.7 & _- & _- & _- & _- & _- \\
\hline Non-Africans & 13.4 & 3.12 & 2.07 to 4.70 & 2.44 & 1.52 to 3.91 & $<0.001$ \\
\hline \multicolumn{7}{|l|}{ Age group (years) } \\
\hline 17 or over & 4.7 & _- & _- & _ & _- & _ \\
\hline $14-16$ & 5.2 & 1.11 & 0.76 to 1.62 & 0.91 & 0.61 to 1.34 & 0.627 \\
\hline $11-13$ & 14.1 & 3.33 & 2.01 to 5.50 & 1.78 & 1.00 to 3.15 & 0.049 \\
\hline \multicolumn{7}{|l|}{ Sex } \\
\hline Male & 4.5 & _- & _- & - & _- & _- \\
\hline Female & 7.2 & 1.63 & 1.16 to 2.30 & 1.50 & 1.06 to 2.14 & 0.024 \\
\hline \multicolumn{7}{|l|}{ Father's education } \\
\hline Up to and including secondary school only & 4.7 & _- & _ & _- & _ & _ \\
\hline Post-secondary (after form 4 or after form 6 ) & 7.4 & 1.61 & 1.12 to 2.31 & 1.63 & 1.20 to 2.40 & 0.010 \\
\hline Unknown or father dead & 4.2 & 0.89 & 0.50 to 1.59 & 0.94 & 0.52 to 1.68 & 0.823 \\
\hline \multicolumn{7}{|l|}{ Sibling wears spectacles } \\
\hline Sibling(s) without spectacles & 4.8 & _ & _- & _- & _ & _ \\
\hline Sibling(s) with spectacles & 8.1 & 1.76 & 1.22 to 2.54 & 1.48 & 1.02 to 2.16 & 0.041 \\
\hline Only child & 16.0 & 3.82 & 1.28 to 11.36 & 1.93 & 0.60 to 6.15 & 0.267 \\
\hline
\end{tabular}

* Crude odds ratio.

†Odds ratio simultaneously adjusted for all other significant independent risk factors: sex, age group, ethnic group, father's education, and siblings wearing spectacles.

\section{Table 5 Relation between myopia and reported near work}

\begin{tabular}{|c|c|c|c|c|c|c|c|c|}
\hline \multirow[b]{2}{*}{ Near work (hours per week) } & \multicolumn{4}{|c|}{ Africans $(n=2258)$} & \multicolumn{4}{|c|}{ Non-Africans $(n=253)$} \\
\hline & $\begin{array}{l}\text { Non-myopic } \\
\text { median } \\
(\mathrm{n}=2151)\end{array}$ & $\begin{array}{l}\text { Myopic } \\
\text { median } \\
(\mathrm{n}=107)\end{array}$ & p Value* & $\begin{array}{l}\text { Quality } \\
\text { control } \\
\text { kappa†ł } \\
(\mathrm{n}=217)\end{array}$ & $\begin{array}{l}\text { Non-myopic } \\
\text { median } \\
(\mathrm{n}=219)\end{array}$ & $\begin{array}{l}\text { icMyopic } \\
\text { median } \\
(n=34)\end{array}$ & $p$ Value* & $\begin{array}{l}\text { Quality control } \\
\text { kappałł } \\
(\mathrm{n}=17)\end{array}$ \\
\hline \multicolumn{9}{|l|}{ (1) Reading for pleasure } \\
\hline term & 2 & 2 & 0.312 & 0.56 & 3 & 4.5 & 0.017 & 0.73 \\
\hline holidays & 3 & 3 & 0.978 & 0.53 & 3 & 7 & 0.014 & 0.73 \\
\hline term and holidays§ & 2.3 & 2 & 0.362 & 0.57 & 3 & 5.5 & 0.010 & 0.73 \\
\hline last week (term time) & 2 & 2 & 0.436 & 0.62 & 2 & 2 & 0.086 & 0.90 \\
\hline \multicolumn{9}{|l|}{ (2) Studying } \\
\hline term & 20 & 20 & 0.624 & 0.53 & 14 & 14 & 0.984 & 0.69 \\
\hline holidays & 15 & 14 & 0.110 & 0.39 & 8 & 7 & 0.387 & 0.64 \\
\hline term and holidays§ & 18.5 & 18 & 0.381 & 0.47 & 12 & 12 & 0.665 & 0.62 \\
\hline last week (term time) & 18 & 15 & 0.438 & 0.36 & 12 & 10.5 & 0.456 & 0.65 \\
\hline (3) Reading for pleasure and studying & 21.8 & 20.8 & 0.344 & 0.34 & 15.8 & 17.5 & 0.540 & 0.35 \\
\hline \multicolumn{9}{|c|}{ (4) Television } \\
\hline term & 3 & 3 & 0.384 & 0.50 & 7 & 8 & 0.521 & 0.56 \\
\hline holidays & 5 & 5 & 0.674 & 0.48 & 14 & 11.5 & 0.799 & 0.72 \\
\hline last week (term) & 3 & 3 I & 0.628 & 0.48 & 5 & 6.5 & 0.351 & 0.68 \\
\hline \multicolumn{9}{|l|}{ (5) Computer } \\
\hline term & $<1$ & $<1$ & 0.463 & 0.45 & 1 & 2 & 0.080 & 1.00 \\
\hline holidays & $<1$ & $<1$ & 0.586 & 0.62 & 2 & 3 & 0.120 & 0.81 \\
\hline last week (term) & $<1$ & $<1$ & 0.340 & 0.35 & 1 & 1 & 0.232 & 1.00 \\
\hline \multicolumn{9}{|l|}{ (6) Sewing } \\
\hline term & $<1$ & $<1$ & 0.331 & -0.01 & $<1$ & $<1$ & 0.869 & 1.00 \\
\hline holidays & $<1$ & $<1$ & 0.168 & 0.44 & $<1$ & $<1$ & 0.778 & 1.00 \\
\hline last week (term) & $<1$ & $<1$ & 0.178 & -0.01 & $<1$ & $<1$ & 0.422 & 1.00 \\
\hline
\end{tabular}

*Wilcoxon's rank sum test for two unpaired samples.

†Grouped in intervals of 5 hours, except for the sewing variables which were grouped in intervals of 4 hours (to avoid all values being in the same group).

flnterpretation of kappa values: $\leqslant 0.20=$ poor agreement, $0.21-0.40=$ fair agreement, $0.41-0.60=$ moderate agreement, $0.61-0.80=$ good

agreement, $0.81-1.00$ very good agreement (13).

$\S$ Term: holidays weighted 3:1.

\N=106.

analysis (Table 3), but were not significant after adjusting for other risk factors in the multivariate analysis.

\section{Significant myopia: associations with near work}

On average, myopic students were slightly younger when they first learned to read ( 6.6 years compared to 6.9 years, $\mathrm{p}=0.012$; two sample $t$ test with equal variances).

Except for one variable (hours of reading for pleasure during the last week; $\mathrm{p}=0.068$ ), the amounts of near work claimed by Africans and non-Africans were significantly different (p:0.013 to $<0.001$; Wilcoxon's rank sum test). The association between myopia and near work was therefore analysed separately for Africans and non-Africans (Table 5).

In African students, the repeatability of the near work questions in the quality control questionnaires ranged from poor to good (Table 5). African students reported spending an average of 2.3 hours per week reading for pleasure and 18.5 hours studying outside school hours. The hours of near work reported per week (reading for pleasure, studying outside school hours, watching television, working on a computer, sewing) were not significantly different in myopes and non-myopes. 
In Non-African students, the repeatability of the near work questions in the quality control questionnaires was generally higher than in Africans and ranged from fair to very good (Table 5). Non-African students reported spending an average of 3.3 hours per week reading for pleasure and 12.0 hours studying outside school hours. Myopic students reported spending 2.5 hours per week more reading for pleasure than non-myopic students $(p=0.017)$. Hours spent studying, watching television, working or playing on a computer, or doing needlework were similar in myopes and non-myopes (Table 5).

\section{Eye consultations and spectacles}

Only 543/2511 (21.6\%) of students reported having had an eye examination in the past. Eye consultations were reported more often by non-African (47.4\%) than by African students $(18.7 \%)(p<0.001$; two sample test of proportions). Almost half of the students with unilateral or bilateral poor eyesight reported that they had never seen an eye professional before $(82 / 174=47.1 \%)$.

Five per cent (126/2511) of students were wearing spectacles when they attended the survey. Of the students with spectacles, about one third $(47 / 126=37.3 \%)$ had significant refractive errors with $\mathrm{VA}<6 / 12$ and about half $(62 /$ $126=49.2 \%$ ) had bilateral visual acuity of $6 / 6$ or $6 / 9$. Only $30.5 \%$ (47/154) of significant refractive errors were corrected. Only two of the three students with severe visual impairment had spectacles before the survey.

\section{DISCUSSION}

\section{Significant refractive errors}

By far the commonest eye problem found in secondary school students in Mwanza City was significant refractive error leading to unilateral or bilateral visual acuity (VA) of worse than $6 / 12$ with a prevalence of $6.1 \%$. Myopia was responsible for $92 \%$ of all significant refractive errors. Since this study used VA of less than 6/12 as a referral criterion for further refraction, lower degrees of hyperopia would have gone undetected. As in primary school students in rural Mwanza Region, strabismus and amblyopia were uncommon. ${ }^{4}$

Many studies have reported the prevalence of refractive errors in children and adolescents of school age. ${ }^{46-29}$ However, many of these studies' results are not directly comparable with the current study, as they were population based ${ }^{14-20}$ were conducted on primary school students, ${ }^{4-6}{ }^{21-23}$ or included both primary and secondary school students ${ }^{24}$ Since the prevalence of myopia increases with education, ${ }^{8}{ }^{14-16}$ direct comparisons should only be made with studies of secondary school students.

The published information on refractive errors in secondary school students shows a wide range of prevalence. This study's prevalence of $6.1 \%$ for significant refractive errors (VA $<6 / 12$ ) and $5.6 \%$ for significant myopia is towards the lower end of the reported range. ${ }^{25-28}$ However, it was considerably higher than in the only other reported sub-Saharan African study of secondary school students in Kaduna, Nigeria, which reported a prevalence of $2.4 \%$ for refractive errors of any degree..$^{25}$

In Mwanza Region of Tanzania, the prevalence of myopia in urban secondary school students was 5.6 times higher than in rural primary schools $(5.6 \% v 1.0 \%) .{ }^{4}$ Even if non-Africans are excluded from the analysis, African secondary school students still had a prevalence of $4.7 \%(v 1.0 \%)$. Since the methodology was the same in both surveys, higher level of education but also differences between rural and urban populations (for example, socioeconomic status, exposure to near work) may be responsible for the difference in myopia prevalence. A study in Nepal found that in children with similar genetic backgrounds, Sherpa children who led a rural lifestyle had a prevalence of myopia of only $2.9 \%$ compared with $21.7 \%$ for Tibetan children who led an urban lifestyle, including more rigorous schooling. ${ }^{29}$

\section{Risk factors for myopia}

In this study, the factors that were found to be independently and significantly associated with myopia were female sex, young age, non-African ethnic origin, higher father's education, and having a history of siblings wearing spectacles (Table 4). These were similar to factors that have been reported to increase the risk of myopia in white and Asian populations. ${ }^{30}$ Only students with visual acuity of less than 6/12 were refracted. Because children with low degrees of myopia were not refracted and have been included in the "non-myopic" group in the risk factor analysis, this may have decreased the strength of the observed association between risk factors and myopia.

Studies on different ethnic groups living in the same environment in Singapore and Hawaii showed considerable variations in the prevalence of myopia. ${ }^{141}$ In the current study in Mwanza, Tanzanian south Asians were 3.6 times more likely to be myopic than Tanzanian Africans $(\mathrm{p}<0.001$, Table 3$)$. In the early 1960s, McLaren and colleagues also reported that the prevalence of myopia in the urban south Asian students aged 7-14 years was higher than in rural African students aged 8-14 years. ${ }^{21}{ }^{23}$ Unfortunately, it is difficult to compare the results from the current study with those of the earlier studies in Mwanza, because different methodologies were used.

Myopia was more common in girls and in children aged $11-13$ years $(p=0.024$ and $p=0.049$, Table 4$)$. Female sex was found to be a risk factor in some other studies ${ }^{10}{ }^{20}$ but most studies found no difference between boys and girls. ${ }^{5} 918193233$ The most likely explanation for the higher prevalence of myopia in children aged 11-13 years was confounding by ethnicity, socioeconomic status, and intelligence, since these children were considerably younger than the minimum age of 14 years for school enrolment in Tanzanian government secondary schools ${ }^{34}$ and nearly half of these children were non-Asians $(78 / 185,42.2 \%)$ compared to $10.1 \%$ in the total study population $(\mathrm{p}<0.00 \mathrm{l}$; two sample test of proportions). However, the possibility cannot be excluded that the lower prevalence in older age groups was the result of uncorrected significant myopia that had caused myopic students to leave school as a result of underachievement.

Studies in China and North America have suggested that juvenile onset myopia may be inherited as a complex trait involving genetic and environmental factors. ${ }^{35-37}$ If true, myopia should cluster in families. In our population, myopia was more common in students who had siblings with spectacles $(p=0.04)$. In the United Kingdom, myopia was found to be more prevalent in non-manual families. ${ }^{33}$ This matches the finding that the Mwanza students whose father had postsecondary education were more likely to be myopic $(p=0.01)$.

Near work has been shown to be associated with myopia in several populations worldwide. ${ }^{97}{ }^{38}$ In our study, no significant difference was found between myopes and non-myopes in reported hours of near work, except for reading for pleasure in non-Africans where myopes read on average 2.5 hours more per week (Table 5). Even this association was no longer statistically significant after adjusting for the other independent risk factors. The average hours that non-African students reported that they spent studying, reading for pleasure, watching television, and using a computer were fairly similar to those reported by 791 American children enrolled in the Orinda Longitudinal Study of Myopia. ${ }^{39}$

On average, African students reported spending a considerably longer time studying (20 hours per week) than non-African students ( 13 hours per week). However, many students, especially Africans, appeared to have great difficulty calculating the number of hours spent studying. The levels of agreement between the original and the quality control questionnaire for the various measures of near work were mainly in the fair or moderate range (Table 5). This casts doubt on the validity of this information in Africans, and may explain the lack of association between near work and myopia among the African students. 
Even though this study tried to adjust for known socioeconomic factors in the multivariate analysis, residual confounding cannot be excluded. All the risk factors for myopia that remained significant in the multivariate analysis were related to higher socioeconomic background. For example, fewer girls than boys reach secondary school, and most who do so are from relatively rich families.

\section{CONCLUSIONS}

In secondary school students in Mwanza City, the overall prevalence of significant refractive errors (with VA worse than $6 / 12$ ) was $6.1 \%$. With best correction, eyesight improved in at least one eye to $6 / 12$ or better in $97 \%$ of students. Even though eye services are relatively widely available in Mwanza City and spectacles are affordable to most secondary school students, only one fifth of students had consulted an eye professional in the past and only one third of the students needing spectacles had them. Thus, the prevalence of uncorrected significant refractive errors was $4.2 \%$. As found in a British study in children under 8 years of age, improvement in vision did not seem to be the only, or even the main, reason for students buying spectacles; for example, half of the students wearing spectacles had uncorrected bilateral VA of $6 / 6$ or $6 / 9 .{ }^{40}$ Spectacles were very popular with students, as long as the frames were fashionable. Given the high prevalence of significant refractive errors, the accessibility of most secondary schools which are mainly situated in urban centres, and the acceptability and affordability of spectacles among secondary school students, an eye screening programme for significant refractive errors is indicated in this population. Furthermore, regular eye screening would also lead to increased awareness of myopia in school age children and may increase the proportion of children seeking care appropriately. A survey of refractive errors in urban primary schools would determine whether the prevalence of myopia is high enough to justify their inclusion in a screening programme.

The great majority of significant refractive errors were due to myopia, with a prevalence of $5.6 \%$. Risk factors for myopia in this Tanzanian secondary school population are similar to these reported in European, North American, and Asian populations-namely, education, Asian ethnicity, family history of myopia, and father's education. An association with near work could not be shown but many students struggled to estimate the number of hours they spent on near work. Alternative methods for assessing the hours of near work, such as the use of diaries, should be considered in future studies in similar populations. ${ }^{41}$

\section{ACKNOWLEDGEMENT}

We thank the rotary clubs of Melton Mowbray, Carlton, Mwanza, and International Rotary for their support.

\section{Authors' affiliations}

S H Wedner, Hindu Union Hospital, Mwanza, Tanzania

D A Ross, J Todd, A Anemona, A Foster, Infectious and Tropical Diseases Department, London School of Hygiene and Tropical Medicine, London, UK

D A Ross, A Anemona, R Balira, Mwanza Research Centre, National Institute for Medical Research, Mwanza, Tanzania

\section{REFERENCES}

1 Cummings GE. Vision screening in junior schools. Public Health 1996;1 10:369-72.

2 Stewart-Brown SL, Brewer R. The significance of minor defects of visual acuity in school children:implications for screening and treatment. Trans Ophthalmol Soc UK 1986;105:287-95.

3 Jewell G, Reeves B, Saffin K, et al. The effectiveness of vision screening by school nurses in secondary schools. Arch Dis Child 1994;70:14-18.

4 Wedner SH, Ross DA, Balira R, et al. A prevalence survey of eye diseases in primary school children in a rural area of Tanzania. $\mathrm{Br} J$ Ophthalmol 2000;84:1291-7.
5 Lewallen $S$, Lowdon $R$, Courtright $P$, et al. A population-based survey of the prevalence of refractive error in Malawi. Ophthalmic Epidemiol 1995;2:145-9

6 Gilbert CE. A pilot study to evaluate logistics and methods for a prevalence and causes survey of visual impairment and hearing impairment in children. London: unpublished report to the Ministry of Health, Gaborone, Botswana, 1995: 1-34.

7 Yap M, Wu M, Liu ZM, et al. Role of heredity in the genesis of myopia. Ophthalmic Physiol Opt 1993;13:316-9.

8 Teasdale TW, Fuchs J, Goldschmidt E. Degree of myopia in relation to intelligence and educational level. Lancet 1988;2:1351-4.

9 Yap M, Wu M, Wang SH, et al. Environmental factors and refractive errors in Chinese school children. Clin Exp Optom 1994;77:8-14

10 Angle J, Wissmann DA. The epidemiology of myopia. Am J Epidemiol 1980; 111:220-8

11 The Planning Commission Dar es Salaam and The Regional Commissioner's Office, Mwanza. Mwanza Region Socio-Economic Profile. Tanzania: Government of the United Republic of Tanzania. Profile. Tanzania: Government of the United Rep
Regional Socio-Economic Profiles, 1997:1-220.

12 Saw SM, Nieto FJ, Katz J, et al. Distance, lighting, and parental beliefs:understanding near work in epidemiologic studies of myopia. Optom Vis Sci 1999:76:355-62.

13 Altman DG. Some common problems in medical research. In: Practical statistics for medical research. 1st ed. London: Chapman and Hall, 1991:396-439.

14 Au Eong KG, Tay TH, Lim MK. Education and myopia in 1 10,236 young Singaporean males. Singapore Med J 1993;34:489-92.

15 Sperduto RD, Seigel D, Roberts J, et al. Prevalence of myopia in the United States. Prevalence of myopia in the United States. Arch Ophthalmol 1983;101:405-7.

16 Chew SJ, Chia SC, Lee LK. The pattern of myopia in young Singaporean men. Singapore Med J 1988;29:201-11.

17 Dandona R, Dandona L, Naduvilath TJ, et al. Refractive errors in an urban population in Southern India:the Andhra Pradesh Eye Disease Study. Invest Ophthalmol Vis Sci 1999;40:2810-8.

18 Maul E, Barroso S, Munoz SR, et al. Refractive error study in children results from La Florida, Chile. Am J Ophthalmol 2000;129:445-54.

19 Pokharel GP, Negrel AD, Munoz SR, et al. Refractive error study in children: results from Mechi Zone, Nepal. Am J Ophthalmol 2000; 129:436-44

20 Zhao J, Pan X, Sui R, et al. Refractive error study in children: results from Shunyi District, China. Am J Ophthalmol 2000;1 29:427-35.

21 McLaren D. The refraction of Indian school children. A comparison of data from East Africa and India. Br J Ophthalmol 1961:45:604-13.

22 Macfarlane DJ, Fitzgerald WJ, Stark DJ. The prevalence of ocular disorders in 1000 Queensland primary schoolchildren. Aust NZ J Ophthalmol 1987;15:161-74.

23 Johnstone WW, McLaren DS. Refraction anomalies in Tanganyikan children. Br J Ophthalmol 1963:47:95-103.

24 Lithander J. Prevalence of myopia in school children in the Sultanate of Oman: a nation-wide study of 6292 randomly selected children. Acta Ophthalmol Scand 1999;77:306-9.

25 Abiose A, Bhar IS, Allanson MA. The ocular health status of postprimary school children in Kaduna, Nigeria: report of a survey. J Pediatr Ophthalmol Strabismus 1979;17:337-40.

26 Grosvenor T. Myopia in Melanesian school children in Vanuatu. Acta Ophthalmol Suppl 1988;185:24-8.

27 Zylbermann R, Landau D, Berson D. The influence of study habits on myopia in Jewish teenagers. J Pediatr Ophthalmol Strabismus 1993;30:319-22.

28 Lin LL, Shih YF, Tsai CB, et al. Epidemiologic study of ocular refraction among schoolchildren in Taiwan in 1995. Optom Vis Sci 1999;76:275-81

29 Garner LF, Owens H, Kinnear RF, et al. Prevalence of myopia in Sherpa and Tibetan children in Nepal. Optom Vis Sci 1999;76:282-5.

30 Saw SM, Katz J, Schein OD, et al. Epidemiology of myopia. Epidemiol Rev 1996;18:175-87

31 Ashton GC. Nearwork, school achievement and myopia. J Biosoc Sci 1985;17:223-33.

32 Robinson BE. Factors associated with the prevalence of myopia in 6-year-olds. Optom Vis Sci 1999;76:266-71.

33 Peckham CS, Gardiner PA, Goldstein H. Acquired myopia in 11-year-old children. BM 1977;1:542-5.

34 Ministry of Education and Culture, Tanzania. Basic statistics in education. Tanzania: The Ministry of Education and Culture Dar es Salaam, 1999: 1-48

35 Pacella R, McLellan J, Grice K, et al. Role of genetic factors in the etiology of juvenile-onset myopia based on a longitudinal study of refractive error. Optom Vis Sci 1999;76:381-6.

36 Wu MM, Edwards MH. The effect of having myopic parents:an analysis of myopia in three generations. Optom Vis Sci 1999;76:387-92.

37 The Framingham Offspring Eye Study Group. Familial aggregation and prevalence of myopia in the Framingham Offspring Eye Study. Arch Ophthalmol 1996;1 14:326-32.

38 Richler A, Bear JC. Refraction, near-work and education. Acta Ophthalmol 1980;58:468-78.

39 Zadnik K, Mutti DO In: Rosenfield M, Gilmartin B, eds. Myopia and nearwork. Oxford: Butterworth-Heinemann, 1998:13-30.

40 Horwood AM. Compliance with first time spectacle wear in children under eight years of age. Eye 1998;12( Pt 2): 173-8.

41 Saw SM, Nieto FJ, Katz J, et al. Estimating the magnitude of close-up work in school-age children:a comparison of questionnaire and diary instruments. Ophthalmic Epidemiol 1999;6:291-301. 